\title{
The Morphometrical Analysis of the External Carotid Artery and its Branches with Multidetector Computerized Tomography Angiography Technique
}

\author{
Análisis Morfométrico de la Arteria Carótida Externa y sus Ramas Mediante \\ la Técnica de Angiografía por Tomografía Computarizada Multidetector
}

Musa Acar*; Ahmet Salbacak**; Mehmet Emin Sakarya ${ }^{* * *}$; Ismail Zararsiz ${ }^{* * * * *}$ \& Mahinur Ulusoy ${ }^{* * * * *}$

ACAR, M; SALBACAK, A; SAKARYA, M. E.; ZARARSIZ, I. \& ULUSOY, M. The morphometrical analysis of the external carotid artery and its branches with multidetector computerized tomography angiography technique. Int. J. Morphol., 31(4):1407-1414, 2013.

SUMMARY: The external carotid artery (ECA) is the main artery of the head and the neck region. Carotid bifurcation (CB), which is one of the place where the atherosclerotic plaques are most commonly seen. The surgical procedure of these plaques which causes cerebral vascular accident (CVA) is carotid endarterectomy. In this surgical procedure, the knowledge of the anatomical courses and variations of the carotid artery increased the surgery performance. In our study, we aimed to introduce the course, the location and the variation of the ECA's and their branches. This study is carried out on multidetector computerized tomography angiography of the ECA's of 50 men and 50 women, totally 200 ECA's (100 right, 100 left). The measurement of the inner diameter of the common carotid artery (CCA) and the ECA was evaluated. The location of the CB was determined and its vertical distance to the gonion measured. We found that the superior thyroid artery (STA) originated from the CCA, the CB and the ECA. The vertical distances between the CB and the STA, lingual (LA), facial (FA) occipital (OA) were measured. The ECA and its branches were recorded. We believe that the assessment of the ECA morphometrically may comprise control groups of diseases related to the vessel diameter and this data may be used as reference in clinic and surgery. Knowing the anatomical details and variations is vital to prevent unpredictable complications in surgery.

KEY WORDS: External carotid artery; Multidetector computerized tomography; Variation; Anatomy.

\section{INTRODUCTION}

The neck region is of great vital value because of the link between head and trunk, upper limb. The thyroid gland, trachea, jugular veins and carotid arteries are vital organs and do not have protective osseous structure like other system so they are very vulnerable to firearm and knife injuries, the blood vessel and the nerves are commonly damaged in this area (Moore \& Dalley, 2007; Ozgur et al., 2008a).

The external carotid artery, feeds the structures of the face, the scalp, upper part of the thyroid gland and some part of the dura mater, is main artery of the head and neck region (Mahendrakar, 2007; Mamatha et al., 2003). The ECA, which is one of the two arteries of the CCA, bifurcate at the level of the (superior margin of the) thyroid cartilage from the CCA which is known carotid bifurcation (CB). The common carotid artery divides into ECA and ICA at the carotid triangle, and locates the anteromedial of the ICA so the anterior branches of the ECA do not cross ICA. The ECA gives immediately its branches as the superior thyroid artery, ascending pharyngeal artery, LA, FA, OA, posterior auricular artery, superficial temporal artery, maxillary artery respectively, after at the level of the CB (Moore \& Dalley).

The carotid bifurcation is the place in where atherosclerotic plaque is most commonly seen. Stenosis of the carotid arteries is important cause of the CVA. The formation of the atherosclerotic plaques is closely related to the anatomy of the CB which effects cervical blood flow (Takahashi et al., 1997; Schulz \& Rothwell, 2001; Furlan et al., 2007; Hayashi et al., 2005). The most common treatment of these plaques, which causes the CVA, is endartrectomy.

\footnotetext{
Mevlana University, Department of Physical Therapy and Rehabilitation, Konya, Turkey.

** Necmettin Erbakan University Meram, Faculty of Medicine Department of Anatomy, Konya, Turkey.

*** Necmettin Erbakan University Meram, Faculty of Medicine Department of Radiology, Konya, Turkey.

***** Mevlana University, Faculty of Medicine, Department of Anatomy, Konya, Turkey.
} 
Surgical procedures require that both atherosclerotic plaques and tunica intima are removed. In this type of surgical procedure, knowing the details of the anatomy and variations of the carotid arteries may increase the surgical success. Knowledge about the CCA, ECA and its branches and variations show that they are very important in radiologic diagnosis and surgery (Gluncic et al., 2001). Ligation of the ECA is performed in case of unstoppable bleeding of arteries which originated the ECA. Similarly in surgery performed in the carotid trigonum, the knowledge of the anatomy is necessary (Gluncic et al.; Hayashi et al.).

In this study we evaluated the morphometric analysis of ECA and its branches, the properties, the origin of the branches and variations of bifurcation in adults. We aimed to compare these feature according to sex and the sides, to detect the prevalence and to provide helpful information for surgery intervention performed in these areas in the scope of the obtained data.

\section{MATERIAL AND METHOD}

This study was carried out on images obtained with multidetector CT angiography (MDCTA) technique, from 200 sample (100 right, 100 left) of 100 patients ( 50 men, 50 women) who were referred to the $\mathrm{CT}$ angiography, did not have any carotid artery disease, in the Department of Radiodiagnostics, Faculty of Medicine, Necmettin Erbakan University.

We planned our study as three stage; the preparation of materials, the assessment of the ECA and its branches and the examining its variations, and statistical analysis. All of the stage was performed by the same researcher to minimize the risk of error.

In first stage of the study; patients who previously consulted the hospital and underwent MDCTA of the head and neck region by using 64 slice-MDCT system (Siemens Somatom Sensation, Erlanger, Almanya, 2005) were identified. Then the volumetric and sub-volumetric images which could be appropriate to assess the arterial structure reformatted in the sagittal, coronal, axial plane with MIP (maximum intensity projection), MPR (multiplanar reformation) and VRT (volume rendering technique) were identified. The measurements were performed on these samples. All patients were in supine position when they were examined by the MDCTA so the standardized data were obtained. The obtained standardized data is important for the reliability of the study.
The measurement of the inner diameter of the CCA and ECA was performed with reformatted axial images (Fig. 1). In multi-planar images; the position of the $\mathrm{CB}$ according to the cervical (C) vertebrae levels (Fig. 2) and the position of the $\mathrm{CB}$ according to the hyoid bone (at lower, higher or at the level) (Fig. 2) were identified, the vertical distance between the $\mathrm{CB}$ and the gonion (CB-gonion) was measured. The artery which originated from STA was identified (CCA, $\mathrm{CB}, \mathrm{ECA})$. The vertical distances between the STA and the $\mathrm{CB}$ (STA-CB), the LA and the CB (LA-CB), the FA and the $\mathrm{CB}$ (FA-CB), the $\mathrm{OA}$ and the $\mathrm{BC}(\mathrm{OA}-\mathrm{BC})$ were measured.

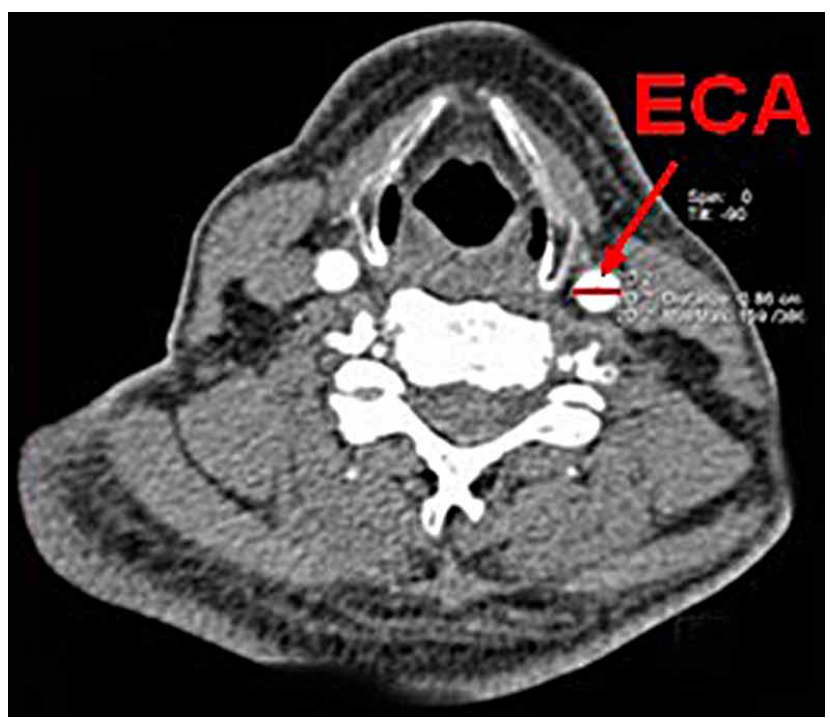

Fig. 1. The measurement of inner diameter of the external carotid artery (ECA).

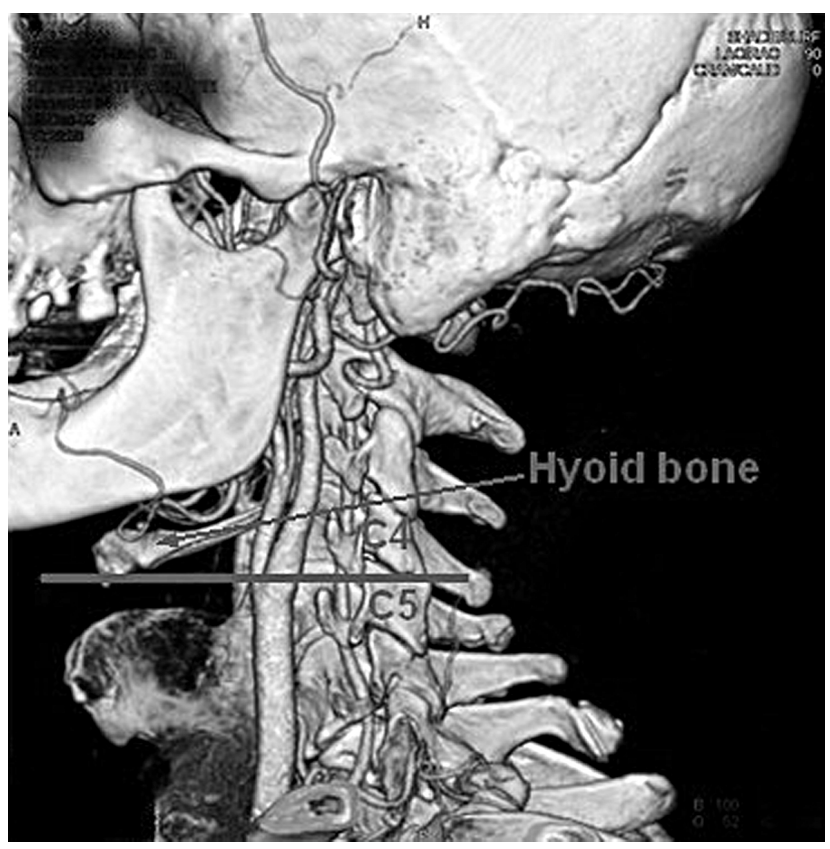

Fig. 2. The position of the $\mathrm{CB}$ according to the cervical (C) vertebrae levels and the hyoid bone. 
Meanwhile the anatomic variations were studied on these images. Thus, the second stage of our study was completed. In the third stage of our study, the obtained data were analyzed with S.P.S.S. 14.0 (Statistical Package for the Social Sciences) packed program. The obtained data are expressed as mean \pm SD and percentage. Normal distribution assumption was evaluated by using Kolmogorov-Smirnov test. Student-t test was used to compare groups, Pearson correlation test was used for relation between parameters. Mann-Whitney U test was used to compare medians of nonnormal distribution, Wilcoxon $\mathrm{W}$ test was used to analyze non-parametric independent variables.

\section{RESULTS}

Our findings were presented as three main title; the findings related to the $\mathrm{CCA}$, the $\mathrm{BC}$ and, the ECA and its branches. All of the data were categorized according to the sexes (men-women) and the sides (the right-the left). Subjects with the anatomic variations were excluded while parameters were measured.

The Findings related to the CCA. Inner diameter of the CCA which is $1 \mathrm{~cm}$ below the $\mathrm{CB}$ was measured as millimeter. Mean values were $6.78 \pm 1.03 \mathrm{~mm}$ at the right side and $6.70 \pm 1.13 \mathrm{~mm}$ at the left side in women and 7.56 $\pm 1.46 \mathrm{~mm}$ at the right side and $7.71 \pm 1.43 \mathrm{~mm}$ at the left side in men. These data were compared according to the sex and the sides. While there were statistically significant differences between sex in both sides $(p<0.05)$, No significant differences were observed with the lateralization (Tables I and II).

The findings related to the $\mathrm{CB}$. The vertical distance of the $\mathrm{CB}$ to the gonion in horizontal plane was measured. The mean values of them at the right side is $16.06 \pm 8.48$ $\mathrm{mm}$, and at the left side is $16.19 \pm 7.86 \mathrm{~mm}$ in women, at the right side is $22.02 \pm 9.20 \mathrm{~mm}$, and at the left is $22.40 \pm$ $10.71 \mathrm{~mm}$ in men and there were no sex differences in the vertical distance of the $\mathrm{CB}$ to the gonion in horizontal plane $(\mathrm{p}<0.05)$. Also there were no significant differences in lateralization (Table II). Carotid bifurcation level was compared to the level of cervical vertebra and their frequency was expressed as percentages. We found that the $\mathrm{CB}$ was between $\mathrm{C} 2$ and $\mathrm{C} 3$ in 14 subjects $(7.03 \%)$, was at C3 level in 39 subjects $(19.59 \%)$, between $\mathrm{C} 3$ and $\mathrm{C} 4$ in 69 subjects (34.67\%), was at C4 level in 44 subjects $(22.11 \%)$, was between $\mathrm{C} 4$ and $\mathrm{C} 5$ in 17 subjects $(8.54 \%)$, was at C5 level in 16 subjects $(8.04 \%)$. Additionally, we evaluated location of the $\mathrm{CB}$ according to the hyoid bone. The $\mathrm{CB}$ was lower than the level of the hyoid bone in $38(19.09 \%)$, was at the level of the hyoid bone in 65 subjects $(32.66 \%)$ and was higher than the level of the hyoid bone in 96 subjects $(48.24 \%)$. The distance between the CB and STA was measured in 99 subjects, who have not anatomic variation of the STA and their STA was originated from ECA. We found that the mean distance between the CB and the STA were $4.83 \pm 2.82 \mathrm{~mm}$ at the right side and $4.03 \pm 2.73 \mathrm{~mm}$ at the left side in women, were $5.54 \pm 3.98 \mathrm{~mm}$ at the right side, $5.79 \pm 2.73 \mathrm{~mm}$ at the left $\mathrm{mm}$ in men. While no statistically significant relation was found at the right side, there were statistically significant differences at the left side $(\mathrm{p}<0.05)$. No statistically significant differences were observed in lateralization (Table II).

The vertical distance between the LA and the CB was measured in 149 samples, 51 samples have variations. We found that the distance between the LA and CB were 14.03 $\pm 7.22 \mathrm{~mm}$ at the right side and $12.97 \pm 5.60 \mathrm{~mm}$ at the left side in women, were $15.60 \pm 6.70 \mathrm{~mm}$ at the right side, 14.93 $\pm 5.53 \mathrm{~mm}$ at the left $\mathrm{mm}$ in men. There were no statistically significant differences both between women and men, and lateralization (Tables I and II). While the vertical distance between the FA and the CB was measured, 47 samples were

Table I. Comparison of the obtained data according to sex (mean \pm SD) (mm).

\begin{tabular}{lccccccr}
\hline \multirow{2}{*}{ Parameters } & \multicolumn{2}{c}{ Female } & \multirow{2}{c}{ Male } & & Female & Male & \multirow{2}{*}{ P } \\
\cline { 2 - 3 } & \multicolumn{2}{c}{ Right } & & \multicolumn{2}{c}{ Left } & \\
\hline CCA $_{\text {ID }}$ & $6.78 \pm 1.03$ & $7.56 \pm 1.46$ & $<\mathbf{0 . 0 5}$ & $6.70 \pm 1.13$ & $7.71 \pm 1.43$ & $<\mathbf{0 . 0 5}$ \\
CB-Gonion & $16.06 \pm 8.48$ & $22.02 \pm 9.20$ & $<\mathbf{0 . 0 5}$ & $16.19 \pm 7.86$ & $22.40 \pm 10.71$ & $<\mathbf{0 . 0 5}$ \\
ICA $_{\text {ID }}$ & $5.42 \pm 1.33$ & $6.38 \pm 1.22$ & $<\mathbf{0 . 0 5}$ & $6.00 \pm 1.45$ & $6.85 \pm 1.72$ & $<\mathbf{0 . 0 5}$ \\
ECA $_{\text {ID }}$ & $4.97 \pm 1.15$ & $5.72 \pm 1.23$ & $<\mathbf{0 . 0 5}$ & $5.24 \pm 1.35$ & $5.92 \pm 1.35$ & $<\mathbf{0 . 0 5}$ \\
STA-CB & $4.83 \pm 2.82$ & $5.54 \pm 3.98$ & $>0.05$ & $4.03 \pm 2.73$ & $5.79 \pm 2.73$ & $<\mathbf{0 . 0 5}$ \\
LA-CB & $13.97 \pm 6.05$ & $15.60 \pm 6.70$ & $>0.05$ & $12.97 \pm 5.60$ & $14.93 \pm 5.53$ & $>0.05$ \\
FA-CB & $21.28 \pm 6.12$ & $24.52 \pm 8.71$ & $<\mathbf{0 . 0 5}$ & $18.84 \pm 6.55$ & $22.03 \pm 7.99$ & $<\mathbf{0 . 0 5}$ \\
OA-CB & $18.19 \pm 10.65$ & $24.60 \pm 16.77$ & $<\mathbf{0 . 0 5}$ & $19.76 \pm 12.15$ & $22.02 \pm 11.25$ & $>0.05$ \\
\hline
\end{tabular}

$\mathrm{CCAID}=$ inner diameter of the common carotid artery, $\mathrm{CB}=$ carotid bifurcation, ICAID $=$ inner diameter of the internal carotid artery, ECAID= inner diameter of the external carotid artery, STA= superior thyroid artery, LA= lingual artery, $\mathrm{FA}=$ facial artery, $\mathrm{OA}=$ occipital artery. 
Table II. Comparison of the obtained data according to lateralization $(\mathrm{mean} \pm \mathrm{SD})(\mathrm{mm})$.

\begin{tabular}{lrrr}
\hline Parameters & Female & \multicolumn{1}{c}{ Male } & P \\
\hline CCA $_{\text {ID }}$ & $7.17 \pm .32$ & $7.21 \pm 1.38$ & $>0.05$ \\
CB-Gonion & $19.01 \pm 9.29$ & $19.09 \pm 9.69$ & $>0.05$ \\
ICA $_{\text {ID }}$ & $5.89 \pm 1.36$ & $6.43 \pm 1.65$ & $<\mathbf{0 . 0 5}$ \\
ECA $_{\text {ID }_{\text {D }}}$ & $5.34 \pm 1.24$ & $5.58 \pm 1.39$ & $>0.05$ \\
STA-CB & $5.21 \pm 3.49$ & $4.80 \pm 2.84$ & $>0.05$ \\
LA-CB & $14.81 \pm 6.40$ & $14.02 \pm 5.60$ & $>0.05$ \\
FA-CB & $22.99 \pm 7.72$ & $20.49 \pm 7.46$ & $<\mathbf{0 . 0 5}$ \\
OA-CB & $21.35 \pm 14.32$ & $20.84 \pm 11.76$ & $>0.05$ \\
\hline
\end{tabular}

$\mathrm{CCAID}=$ inner diameter of the common carotid artery, $\mathrm{CB}=$ carotid bifurcation, ICAID= inner diameter of the internal carotid artery, ECAID= inner diameter of the external carotid artery, STA= superior thyroid artery, $\mathrm{LA}=$ lingual artery, $\mathrm{FA}=$ facial artery, $\mathrm{OA}=$ occipital artery.

excluded due to having variations. So 147 samples were included this measurement. The distances were $21.28 \pm 6.12$ $\mathrm{mm}$ at the right side and $18.84 \pm 6.55 \mathrm{~mm}$ at the left side in women, were $24.52 \pm 8.71 \mathrm{~mm}$ at the right side, $22.03 \pm$ $7.99 \mathrm{~mm}$ at the left $\mathrm{mm}$ in men. There were statistically significant differences both between women and men, and lateralization (Tables I and II).

The vertical distance between the $\mathrm{OA}$ and the $\mathrm{CB}$ was measured in 199 samples which have no variations. The distance was measured as $18.19 \pm 10.65 \mathrm{~mm}$ at the right side, $19.76 \pm 12.15$ at the left side in women and $24.60 \pm$ $16.77 \mathrm{~mm}$ at the right side, $22.02 \pm 11.25 \mathrm{~mm}$ at the left side in men. There were statistically significant differences in right side $(\mathrm{p}<0.05)$ but not in left side between women and men. However No statistically significant differences were observed in lateralization (Tables I and II).

The findings related to the ECA and its branches. The inner diameter of the ECA at $1 \mathrm{~cm}$ above the $\mathrm{CB}$ was measured as $4.97 \pm 1.15 \mathrm{~mm}$ at the right side, $5.24 \pm 1.35$ $\mathrm{mm}$ at the left side in women, and $5.72 \pm 1.23 \mathrm{~mm}$ at the right side, $5.92 \pm 1.35 \mathrm{~mm}$ at the left side in men. The obtained data were analyzed, according to these data, while there were statistically significant differences in the right and left side both in women and men $(\mathrm{p}<0.05)$, there were no statistically significant differences in lateralization (Tables I and II). The ECA lay differently in $11(5.5 \%)$ subjects (8 women and $3 \mathrm{men}$ ), in these subjects, the ECA lay lateral to the ICA, which is termed as lateral position of the ECA (LPECA) (Fig. 3).

We found that STA was originated from the CCA in $36(18 \%)$ samples, from the CB in 62(31\%) samples and from ECA in 102 (51\%) samples.

We observed that the STA and the LA originated from the ECA with the common trunk known as truncus tyro- lingualis in $4(2 \%)$ samples(2 (2\%) women, $2(2 \%)$ men) (Fig. 4).

We observed that the LA and FA was originated from the ECA with common trunk known as truncus liguo-facialis in 47 (\%23.5) samples (27 (27\%) women, 20 (20\%) men) (Fig. 5).

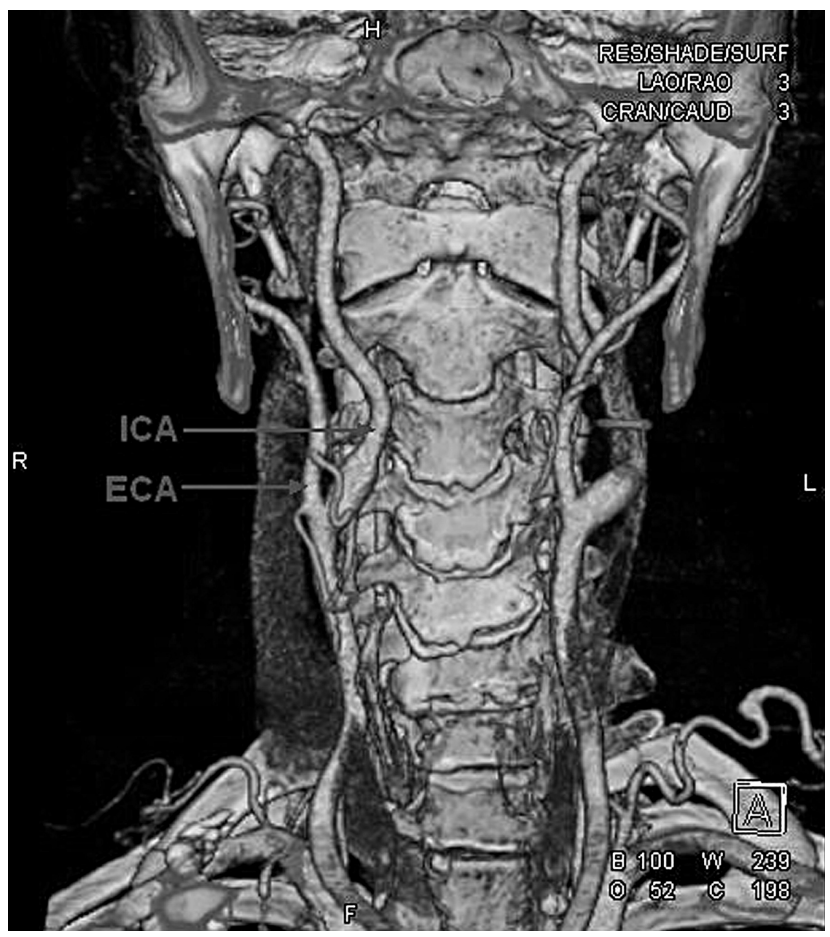

Fig. 3. The lateral position of the external carotid artery (ECA).

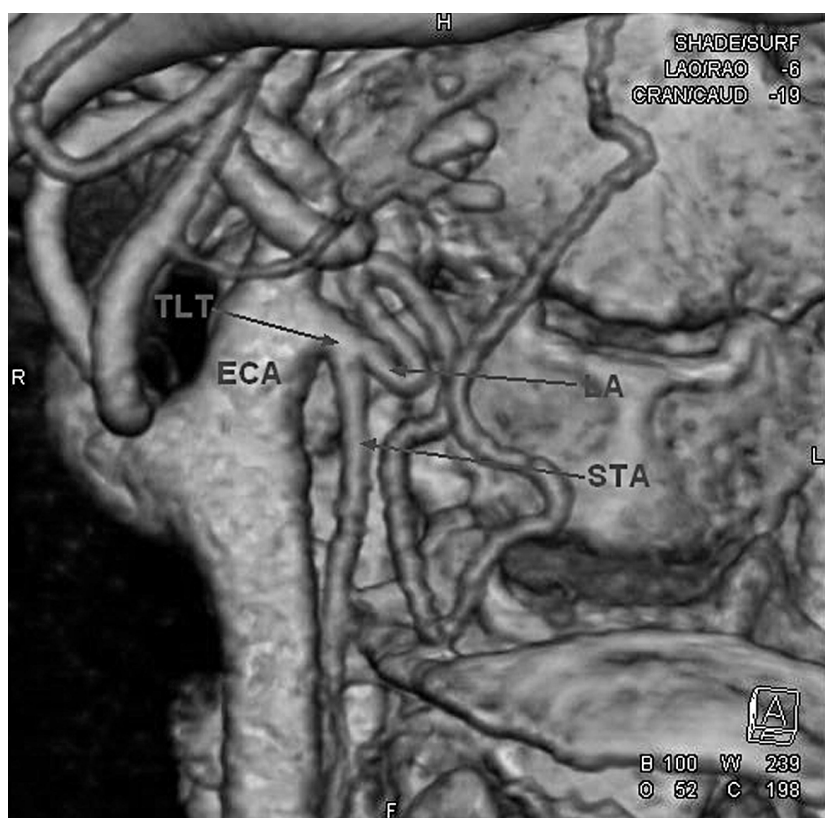

Fig. 4. A case with thyrolingual trunk. 


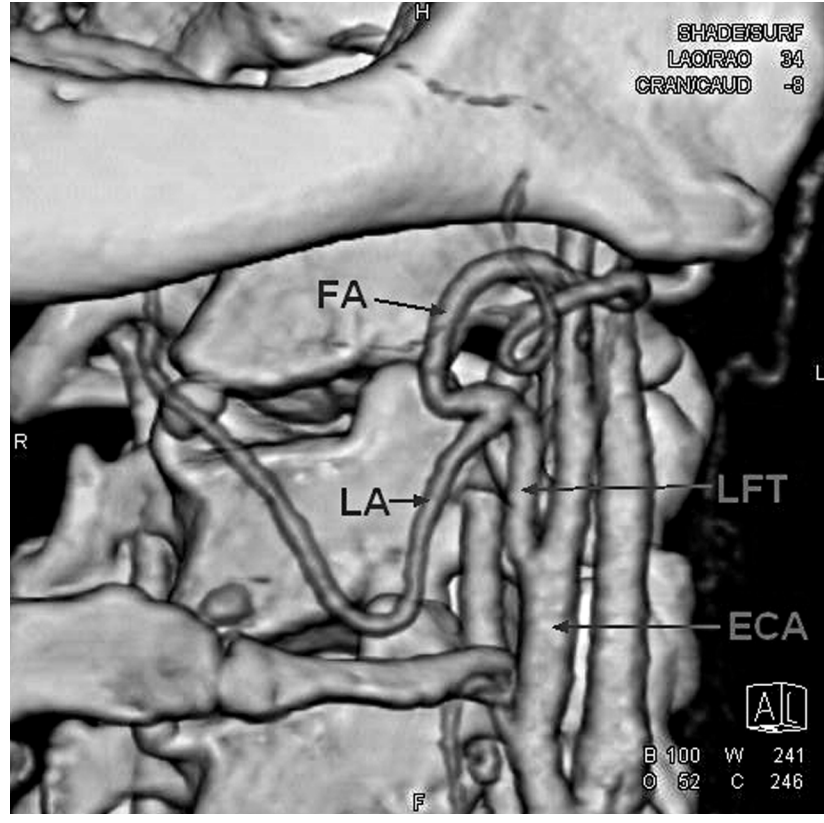

Fig. 5. A case with linguofacial trunk.

In one sample, the occipital artery was separated at the middle of the $\mathrm{CB}$. The OA was originated from almost every levels of the ECA so the obtained data did not present non-normal distribution. Non-parametric tests were used to analyze the data and the values of standard deviations were quite high.

\section{DISCUSSION}

The CCA was studied by the many investigators and they reported that the results of their study were associated with the cardiovascular related risk factors (Kawamoto et al., 2006). The association between atherosclerotic risk factors and luminial diameter is a truism and previous studies suggested that the development of the atherosclerotic plaques compensate for luminal enlargement (Ozdemir et al., 2006; Ruan et al., 2009).

Krejza et al. (2006) reported that the luminal diameter of the CCA was $6.10 \pm 0.80 \mathrm{~mm}$ in women, was $6.52 \pm 0.98$ $\mathrm{mm}$ in men and there were no statistically significant difference between men and women. Kozova et al. (2008) reported that the luminal diameter of the CCA was $5.38 \pm$ $0.52 \mathrm{~mm}$ in women, $6.07 \pm 0.65 \mathrm{~mm}$ in men and there were statistically significant difference between men and women. Johsen et al. (2009) reported that they measured the lumen diameter of the CCA as $6.20 \pm 0.70 \mathrm{~mm}$ in women and 6.70 $\pm 0.90 \mathrm{~mm}$ in men, and they observed statistically significant differences between women and men. In our study, the lumen diameter of the CCA was measured as $6.70 \pm 1.13 \mathrm{~mm}$ in women and $7.71 \pm 1.43 \mathrm{~mm}$ in men. Our findings related to the lumen diameter were similar to those reported in literature and a statistically significant difference was observed between women and men.

Surgical procedures have emphasized the knowing of the anatomical vascular variations of the head and neck region (Klosek \& Rungruang, 2008). Previous studies investigated intensively the relation between the anatomy of the CB and the hemodynamics. These studies reported that the diameter of the vessel and the anatomy of the $\mathrm{CB}$ are important indicative of the development of the atherosclerotic plaques (Schulz \& Rothwell). Carotid bifurcations were found mostly at the $\mathrm{C} 3$ level (50\% right and 55 left) and at the C4 level (40\% right and 35\% left) (Aggarwal et al., 2006; Ooigawa et al., 2006; Thwin et al., 2010). Klosek \& Rungruang studied on 43 cadavers and they reported that most of the carotid bifurcations were between $\mathrm{C} 3$ and $\mathrm{C} 4$. In another study reported that carotid bifurcations found mostly at the level of C3 and at the level of $\mathrm{C} 4$, however in $10 \%$ of cases it was above the level of the $\mathrm{C} 2$ and only in $1 \%$ of cases it was below the level of the C5 (Anu et al., 207). In our study, we found the $\mathrm{CB}$ between $\mathrm{C} 2$ and $\mathrm{C} 3(12 \%)$, at the level of the $\mathrm{C} 3$ (24\%), between C3 and C4 (36\%), at the level of the C4 (14\%), between C4 and C5 (12\%), at the level of the C5 (2\%) at the right side and between $\mathrm{C} 2$ and $\mathrm{C} 3(12 \%)$, at the level of the C3 (26\%), between C3 and C4 (30\%), at the level of the $\mathrm{C} 4(22 \%)$, between $\mathrm{C} 4$ and C5 (6\%), at the level of the $\mathrm{C} 5(4 \%)$ at the left side in women and between C2 and C3 (2.04\%), at the level of the C2 (16.32), between C3 and C4 $(36.73 \%)$, at the level of the C4 $(26.53 \%)$, between C4 and C5 (4.08\%), at the level of the C5 (14.28\%) at the right side and between C2 and C3 (2\%), at the level of the C3 (12\%), between C3 and C4 (36\%), at the level of the C4 (26\%), between C4 and C5 (12\%), at the level of C5 (\%12) at the left side in men. Our study supported the findings of the previous studies which reported that the $\mathrm{CB}$ was found mostly between $\mathrm{C} 3$ and C4.

Lucev et al. (2000) classified the location of the $\mathrm{CB}$ according to the position of the hyoid bone in 20 cadavers and found that the $\mathrm{BC}$ was above the hyoid bone in 10 cases, at the level of the hyoid bone in 5 cases and below the hyoid bone in 5 cases. We found that the $\mathrm{CB}$ were below the hyoid bone in $19.09 \%$ of subjects, at the level of the hyoid bone in $32.66 \%$ of them and above the level of the hyoid bone in 48.24 of them. Our findings suggested that most of the CCA bifurcated above the hyoid bone and these findings were similar to the findings of Lucev et al. study. 
Klosek \& Rungruang reported that the distance between the $\mathrm{CB}$ and the gonion is easily evaluated so they suggest that it should be used in clinical use they found that the distance as $3.3 \pm 0.8 \mathrm{~cm}$ at the right side, $3.1 \pm 1.2 \mathrm{~cm}$ at the left side in women, $3.5 \pm 0.9 \mathrm{~cm}$ at right side, $3.9 \pm 1.2 \mathrm{~cm}$ at the left side in men. Ozgur et al. (2008a) evaluated this distance and it was $36.3 \pm 9.8$ $\mathrm{mm}$ at the right side and, $36.1 \pm 9.2 \mathrm{~mm}$ at the left side. Our findings were $16.06 \pm 8.48 \mathrm{~mm}$ at the right side, 16.19 $\pm 7.86 \mathrm{~mm}$ at the left side in women and $22.02 \pm 9.20$ $\mathrm{mm}$ at the right side, $22.40 \pm 10.71 \mathrm{~mm}$ at the left side in men. Our study presented findings different than those of previous studies.

There are different surgery techniques related to the artery ligation in the carotid triangle. These techniques positioned the ECA and the ICA to the normal anatomic courses. Location of the ECA to the ICA laterally were referred to the lateral position of the external carotid artery (LP-ECA). The hypoglossal nerve which located above the CB may be markedly compressed by the LP-ECA and its location changed laterally so this may cause neurological symptoms (Ergür \& I'cke, 2005; Rusu et al., 2006). The lateral position of the external carotid artery were firstly reported by Hirtl in 1841 in literature. Currently this phenomenon was not common as much as reported previously. Ergür \& I'cke found that the incidence of the subjects with the LP-ECA was \%3.5. Ueda et al. (1984) reported that the incidence of the LP-ECA was $7.9 \%$ on right side, $2.3 \%$ on left side and $1 \%$ on both sides. In our study, the incidence was $5.5 \%, 11$ subjects with the LPECA (8 women, 3 men).

Lo et al. (2006) measured the diameter of the ECA as $5.1 \mathrm{~mm}$. Similarly In our study, the diameter of the ECA was $4.97 \pm 1.15 \mathrm{~mm}$ in women, $5.72 \pm 1.23 \mathrm{~mm}$ in men.

The superior thyroid artery is the surgical landmark for distinguishing the ECA from the ICA. However previous studies reported that the STA was separated from both the $\mathrm{CB}$ and the CCA as distinct from the ECA. The variations in the origin of the STA are very important in surgery. It has been reported that the accepted connection point is the lower part of the STA in the ECA ligation (Lo et al.; Vásquez et al., 2008). Vazquez et al. classified the variations in origin of the STA into three groups in their cadaveric study. According to this classification the STA originates from the $\mathrm{CB}$ is type I, from the CCA is type II and from the ECA is type III. In our study the incidence of the STA for type I was $49 \%$, type II was $26.6 \%$ and type III was $23 \%$. Klosek \& Rungrang found that the STA was originated from the CCA in $26.3 \%$ at the right side, $55.5 \%$ at the left side of women and in $11.7 \%$ at the right side,
$39 \%$ at the left side of men, the remainders were originated from the ECA in their study on 43 cadavers. Özgür et al. (2009) studied in 40 cadavers reported that the STA arising from the level of the CB was $40 \%$, the ECA $25 \%$ and the CCA was \%35. We observed that the origin of the STA originated from the CCA in $14 \%$ of subjects, the BC $35 \%$ and the ECA $\% 51$ of women and from the CCA in $22 \%$ of subjects, the BC $27 \%$ and the ECA $51 \%$ of men. Our findings are not concordant with the literature.

Another variations, the common trunk from the ECA which is define in the literature is thyrolingual trunk, it separates the STA and LA separated from the ECA with common trunk. While Vazquez et al. observed that its frequency was $1 \%$, Zümre et al. (2005) reported that it found in $2.5 \%$ of cases. Hayashi et al. reported its frequency as $1 \%$. We observed it in $2 \%$ of samples and these trunks originated from the ECA.

Lo et al. reported that the mean distance between STA and the BC was $5.9 \mathrm{~mm}$. Özgür et al. (2009) reported that the distance of the STA to the CB was $3.3 \pm 4.3 \mathrm{~mm}$. We measured the distance between the STA to the CB in two groups of subjects, in the first group, STA originated from the ECA and its distance was $4.46 \pm 2.78 \mathrm{~mm}$ in women and $5.63 \pm 3.55 \mathrm{~mm}$ in men, as for the second group, the STA originated from the CCA and its distance was $5.02 \pm 3.55 \mathrm{~mm}$ in women and $4.56 \pm 2.30 \mathrm{~mm}$ in men. In our study we measured the distance from the STA to the $\mathrm{CB}$ according to the origin of the STA either from the ECA or the CCA. The mean distances in originated from the ECA were $4.46 \pm 2.78 \mathrm{~cm}$ in women and $5.63 \pm$ $3.55 \mathrm{~cm}$ in men, and in originated from the CCA were $5.02 \pm 2.96$ in women and $4.56 \pm 2.30$ in men.

Klosek \& Rungruang examined 43 cadavers for the measuring the distance between the LA which is another branch of the ECA and the $\mathrm{CB}$, and found that the mean distances were $1.5 \pm 0.5 \mathrm{~cm}$ (right) and $1.5 \pm 0.5 \mathrm{~cm}$ (left) in women, and $1.72 \pm 0.5 \mathrm{~cm}$ (right) and $1.8 \pm 0.6 \mathrm{~cm}$. Fazan et al. (2009) reported that the mean distances were $1.05 \pm 0.11 \mathrm{~cm}$ at the right side and $1.02 \pm 0.11 \mathrm{~cm}$ at the left side. In the study we found that the mean distances were $13.48 \pm 5.81 \mathrm{~mm}$ in women and $15.26 \pm 6.10 \mathrm{~mm}$ in men.

The facial artery originated from the ECA immediately above the LA (Marx et al., 2008). Lo et al. evaluated the distance between the $\mathrm{CB}$ and the FA and found that the mean distance was $22.9 \mathrm{~mm}$. Ozgür et al. (2008b) evaluated this distance as $19.6 \pm 8.7 \mathrm{~mm}$. In our study we found that the distances were $20.07 \pm 6.41 \mathrm{~mm}$ in women and $23.30 \pm 8.41 \mathrm{~mm}$ in men. 
Previous studied reported that both LA and FA were separated from the ECA with the common trunk known as linguofacial trunk. Fazan et al. studied on 41 cadavers and reported that the frequencies of the linguofacial trunk were $20 \%$ of cases in women and $24 \%$ of cases in men. Hayashi et al. found that there were $18 \%$ of linguofacial trunk cases in their study. We found that the incidence of this case was $27 \%$ in women and $20 \%$ in men.

It is known that the OA is a branch of the ECA. Suzuki et al. (2000) reported that both OA and APA were separated from the ECA by the common trunk. Aggarwal et al. identified that both the OA and the APA separated from ICA in 1 case by using angiography technique. In our study, all of the OA was originated from the ECA, the distance from the $\mathrm{OA}$ to the $\mathrm{CB}$ was $19.76 \pm 12.75 \mathrm{~mm}$ in women and $22.02 \pm 11.25 \mathrm{~mm}$.

The fundamentals of our study consisted of the morphometric measurements which form content of the anatomical study and the evaluating the anatomic variation. We believe that assessment of the ECA in point of morphometry may comprise the control group in diseases affecting vessel diameter and the data may provide to form the future preference to the clinic and the surgery. Knowing anatomic details and variations takes great advantage of preventing unpredictable complications during surgical intervention. We hope that our data may be helpful both in diagnosing and treatment in the scope of presented knowledge.

ACAR, M; SALBACAK, A; SAKARYA, M. E.; ZARARSIZ, I. \& ULUSOY, M. Análisis morfométrico de la arteria carótida externa y sus ramas mediante la técnica de angiografía por tomografía computarizada multidetector. Int. J. Morphol., 31(4):1407-1414, 2013.

RESUMEN: La arteria carótida externa (ACE) es la principal arteria de la cabeza y de la región del cuello. La bifurcación carotídea (BC) es uno de los lugares donde las placas ateroscleróticas son más frecuentes. El procedimiento quirúrgico para tratar estas placas que causan el accidente vascular cerebral (AVC) es la endarterectomía carotídea. En este procedimiento quirúrgico, el conocimiento de los cursos anatómicos y variaciones de la arteria carótida aumenta el rendimiento de la cirugía. El objetivo de nuestro estudio fue presentar el trayecto, localización y variación de la ACE y sus ramas. El estudio se realizó mediante angiografía multidetector por tomografía computarizada de la ACE de 50 hombres y 50 mujeres, totalizando 200 ACE (100 derechas y 100 izquierdas). Se evaluaron el diámetro interior de la arteria carótida común (ACC) y la ACE. Se determinó la ubicación de la BC y se midió la distancia vertical hasta el gonion. Se observó que la arteria tiroidea superior (ATS) se originó desde la ACC, la BC y la ACA. Las distancias verticales entre la BC, y las arterias tiroídea superior, lingual (AL), facial (AF) y occipital (AO) fueron medidas. La ACE y sus ramas se registraron. Creemos que la evaluación morfométrica de la ACE puede comprender grupos de control de las enfermedades relacionadas con el diámetro de los vasos, y estos datos pueden ser utilizados como referencia clínica y quirúrgica. El conocimiento de los detalles anatómicos y variaciones es de vital importancia para evitar complicaciones imprevisibles en la cirugía.

PALABRAS CLAVE: Arteria carótida externa; Tomografía computarizada multidetector ; Variación; Anatomía.

\section{REFERENCES}

Aggarwal, N. R.; Krishnamoorthy, T.; Devasia, B.; Menon, G. \& Chandrasekhar, K. Variant origin of superior thyroid artery, occipital artery and ascending pharyngeal artery from a common trunk from the cervical segment of internal carotid artery. Surg. Radiol. Anat., 28(6):650-3, 2006.

Anu, V. R.; Pai, M. M.; Rajalakshmi, R.; Latha, V. P.; Rajanigandha, V. \& D'Costa, S. Clinically-relevant variations of the carotid arterial system. Singapore Med. J., 48(6):566-9, 2007.

Ergür, I. \& Icke, C. Lateral position of the external carotid artery. DEÜ Tip Fakültesi Dergisi, 19(2):107-10, 2005,

Fazan, V. P.; da Silva, J. H.; Borges, C. T.; Ribeiro, R. A.; Caetano, A. G. \& Filho, O. A. An anatomical study on the lingual-facial trunk. Surg. Radiol. Anat., 31(4):267-70, 2009.

Furlan, J. C.; de Magalhães, R. P.; de Aguiar, E. T. \& Shiroma, S.
Localization of the superior laryngeal nerve during carotid endarterectomy. Surg. Radiol. Anat., 24(3-4):190-3, 2002.

Gluncic, V.; Petanjek, Z.; Marusic, A. \& Gluncic, I. High bifurcation of common carotid artery, anomalous origin of ascending pharyngeal artery and anomalous branching pattern of external carotid artery. Surg. Radiol. Anat., 23(2):123-5, 2001.

Hayashi, N.; Hori, E.; Ohtani, Y.; Ohtani, O.; Kuwayama, N. \& Endo, S. Surgical anatomy of the cervical carotid artery for carotid endarterectomy. Neurol. Med. Chir. (Tokyo), 45(1):259; discussion, 2005.

Johnsen, S. H.; Joakimsen, O.; Singh, K.; Stensland, E.; Forsdahl, S. H. \& Jacobsen, B. K. Relation of common carotid artery lumen diameter to general arterial dilating diathesis and abdominal aortic aneurysms: the Troms $\emptyset$ Study. Am. J. Epidemiol., 169(3):330-8, 2009. 
Kawamoto, R.; Tomita, H.; Oka, Y. \& Ohtsuka, N. Association between risk factors and carotid enlargement. Intern. Med., 45(8):503-9, 2006.

Klosek, S. K. \& Rungruang, T. Topography of carotid bifurcation: considerations for neck examination. Surg. Radiol. Anat., 30(5):383-7, 2008.

Kozakova, M.; Palombo, C.; Paterni, M.; Anderwald, C. H.; Konrad, T.; Colgan, M. P.; Flyvbjerg, A.; Dekker, J. \& Relationship between Insulin Sensitivity Cardiovascular risk Investigators. Body composition and common carotid artery remodeling in a healthy population. J. Clin. Endocrinol. Metab., 93(9):3325-32, 2008.

Krejza, J.; Arkuszewski, M.; Kasner, S. E.; Weigele, J.; Ustymowicz, A.; Hurst, R. W.; Cucchiara, B. L. \& Messe, S. R. Carotid artery diameter in men and women and the relation to body and neck size. Stroke, 37(4):1103-5, 2006.

Lo, A.; Oehley, M.; Bartlett, A.; Adams, D.; Blyth, P. \& Al-Ali, S. Anatomical variations of the common carotid artery bifurcation. ANZ J. Surg., 76(11):970-2, 2006.

Lucev, N.; Bobinac, D.; Maric, I. \& Drescik, I. Variations of the great arteries in the carotid triangle. Otolaryngol. Head Neck Surg., 122(4):590-1, 2000.

Mahendrakar, M. A. Variation in the branching pattern of external carotid artery: a case report. J. Anat. Soc. India, 56:47-51, 2007.

Mamatha, T.; Rai, R.; Prabhu, L. V. \& Hadimani, G.A. Anomalous branching pattern of the external carotid artery: a case report. Rom. J. Morphol. Embryol., 51(3):593-5, 2010.

Marx, C.; Kumar, P.; Reddy, S. \& Vollala, V. R. Bilateral variation of facial artery: a case report. Rom. J. Morphol. Embryol., 49(3):399401, 2008.

Moore, L. K. \& Dalley, F. A. Klinig`e Yönelik Anatomi. Gstanbul, Nobel, 2007. pp.1000-63.

Ooigawa, H.; Nawashiro, H.; Fukui, S.; Tsuzuki, N.; Katoh, H.; Kawaguchi, T.; Kaneko, Y.; Tsutsumi, M.; Kawano, T. \& Shima, K. Non-bifurcating cervical carotid artery. J. Clin. Neurosci., 13(9):944-7, 2006.

Ozdemir, H.; Artas, H.; Serhatlioglu, S. \& Ogur, E. Effects of overweight on luminal diameter, flow velocity and intima-media thickness of carotid arteries. Diagn. Interv. Radiol., 12(3):142-6, 2006.

Ozgur, Z.; Govsa, F. \& Ozgur, T. Assessment of origin characteristics of the front branches of the external carotid artery. J. Craniofac. Surg., 19(4):1159-66, 2008a.

Ozgur, Z.; Govsa, F. \& Ozgur, T. Anatomic evaluation of the carotid artery bifurcation in cadavers: implications for open and endovascular therapy. Surg. Radiol. Anat., 30(6):475-80, 2008 b.
Ozgur, Z.; Govsa, F.; Celik, S. \& Ozgur, T. Clinically relevant variations of the superior thyroid artery: an anatomic guide for surgical neck dissection. Surg. Radiol. Anat., 31(3):151-9, 2009.

Ruan, L.; Chen, W.; Srinivasan, S. R.; Sun, M.; Wang, H.; Toprak, A. \& Berenson, G. S. Correlates of common carotid artery lumen diameter in black and white younger adults: the Bogalusa Heart Study. Stroke, 40(3):702-7, 2009.

Rusu, M. C.; Vasilescu, A. \& Nimigean, V. A rare anatomic variant: the lateral position of the external carotid artery. Int. J. Oral Maxillofac. Surg., 35(11):1066-7, 2006.

Schulz, U. G. \& Rothwell, P. M. Major variation in carotid bifurcation anatomy: a possible risk factor for plaque development? Stroke, 32(11):2522-9, 2001.

Suzuki, T.; Moriyama, T.; Moriwaki, H.; Yagihashi, A.; Yajima, N. \& Takahashi, G. Anomalous artery directly connecting the external and internal carotid arteries. Ann. Anat., 182(1):59-63, 2000.

Takahashi, M.; Ashtari, M.; Papp, Z.; Patel, M.; Goldstein, J.; Maguire, W. M.; Eacobacci, T.; Khan, A. \& Herman, P. G. CT angiography of carotid bifurcation: artifacts and pitfalls in shaded-surface display. AJR Am. J. Roentgenol., 168(3):813-7, 1997.

Thwin, S. S.; Soe, M. M.; Myint, M.; Than, M. \& Lwin, S. Variations of the origin and branches of the external carotid artery in a human cadaver. Singapore Med. J., 51(2):e40-2, 2010.

Ueda, S.; Kohyama, Y. \& Takase, K. Peripheral hypoglossal nerve palsy caused by lateral position of the external carotid artery and an abnormally high position of bifurcation of the external and internal carotid arteries--a case report. Stroke, 15(4):736-9, 1984.

Vázquez, T.; Cobiella, R.; Maranillo, E.; Valderrama, F. J.; McHanwell, S.; Parkin, I. \& Sañudo, J. R. Anatomical variations of the superior thyroid and superior laryngeal arteries. Head Neck, 31(8):1078-85, 2008

Zümre, O.; Salbacak, A.; Cicekcibasi, A. E.; Tuncer, I. \& Seker, M. Investigation of the bifurcation level of the common carotid artery and variations of the branches of the external carotid artery in human fetuses. Ann. Anat., 187(4):361-9, 2005.

Correspondence to:

Musa ACAR, Ph.D.

Department of Physical Therapy and Rehabilitation 42003

Mevlana University

Konya

TURKEY

Email: macar@mevlana.edu.tr

Received: 23-07-2013

Accepted: 10-11-2013 